\title{
O PROCESSO DE CONSTRUÇÃO DE BLOGS POR ALUNOS DO ENSINO FUNDAMENTAL
}

\author{
THE PROCESS OF CONSTRUCTING BLOGS BY STUDENTS OF FUNDAMENTAL EDUCATION \\ EL PROCESO DE CREACIÓN DE BLOGS POR ESTUDIANTES DE EDUCACIÓN FUNDAMENTAL
}

\author{
Luciana de Lima \\ Doutora pela Universidade Federal do Ceará - Fortaleza/CE - Brasil. \\ E-mail: luciana@virtual.ufc.br. \\ Orcid: http://orcid.org/0000-0002-5838-8736. \\ Robson Carlos Loureiro \\ Doutor pela Universidade Federal do Ceará - Fortaleza/CE - Brasil. \\ E-mail: robson@virtual.ufc.br. \\ Orcid: - http://orcid.org/0000-0001-7701-3799 \\ Hiago Bruno da Silva Rabelo \\ Graduado pela Universidade Federal do Ceará - Fortaleza/CE - Brasil. \\ E-mail: contato.hiagobruno@gmail.com. \\ Orcid: https://orcid.org/0000-0002-4231-5567
}

\begin{abstract}
RESUMO
A pesquisa tem como objetivo analisar de que forma os alunos de $7^{\circ}$ ano de instituição de ensino particular utilizam as mídias digitais para a construção de Blog. Pesquisas revelam que os alunos dessa faixa etária apresentam dificuldades no desenvolvimento de Blogs por falta de letramento digital que os permita manipular informações e mídias utilizando esse tipo de recurso. Classificada como pesquisa exploratória qualitativa, utilizou como unidade de análise 23 alunos, subdivididos em 7 grupos no momento do desenvolvimento dos Blogs. Subdividiu-se em três etapas: planejamento, coleta e análise de dados. Na primeira, foram elaborados os instrumentos e preparados os equipamentos para as etapas subsequentes. Na segunda, a coleta foi realizada considerando-se a captação dos conhecimentos prévios dos alunos por meio da aplicação de um questionário de sondagem e os relatórios de observação construídos a partir da produção dos Blogs pelos alunos. Na terceira, a análise de dados ocorreu de forma interpretativa utilizando-se os procedimentos propostos pela Análise Textual Discursiva em cinco fases: unitarização, categorização, descrição, interpretação e argumentação. Identificou-se que os alunos utilizaram o conceito de redes sociais como base para a construção dos Blogs. Apresentaram dificuldades em operar sua interface e compreender sua dinâmica, além de compreender metáforas como o conceito de endereço digital. Pretende-se continuar a investigação ampliando o escopo de alunos dessa faixa etária em contextos de criação e desenvolvimento de Blogs.
\end{abstract}

Palavras-chave: Tecnologia educacional. Tecnologia e didática. Ensino por computador. Aprendizagem. Ensino fundamental.

\begin{abstract}
The research goals to analyze how the 7th year students of a private education institution use digital media to construct a Blog. Research shows that students of this age group have difficulties in developing Blogs due to a lack of digital literacy that allows them to manipulate information and media using this type of resource. Classified as qualitative exploratory research, it used as a unit of analysis 23 students, subdivided into 7 groups
\end{abstract}


at the time of developing the Blogs. It was subdivided into three stages: planning, data collection, and analysis. In the first, the instruments were prepared, and the equipment was prepared for the subsequent steps. In the second, the collection was carried out considering the capture of the students' previous knowledge through the application of a survey questionnaire and the observation reports constructed from the production of Blogs by the students. In the third, the data analysis occurred in an interpretative way using the procedures proposed by the Discursive Textual Analysis in five phases: unitarization, categorization, description, interpretation, and argumentation. It was identified that students used the concept of social networks as a basis for the construction of Blogs. They presented difficulties in operating their interface and understanding its dynamics, in addition to understanding metaphors such as the concept of a digital address. It is intended to continue the investigation expanding the scope of students of this age group in contexts of creation and development of Blogs.

Keywords: Educational technology. Technology and didactic. Teaching by computer. Learning. Fundamental teaching.

\section{RESUMEN}

La investigación tiene como objetivo analizar cómo los estudiantes de $7^{\circ}$ año de una institución educativa privada usan los medios digitales para construir un Blog. La investigación muestra que los estudiantes de este grupo de edad tienen dificultades para desarrollar blogs debido a la falta de alfabetización digital que les permite manipular información y medios utilizando este tipo de recurso. Clasificada como investigación exploratoria cualitativa, utilizó a 23 estudiantes como una unidad de análisis, subdividida en 7 grupos en el momento del desarrollo de los Blogs. Se subdividió en tres etapas: planificación, recopilación de datos y análisis. En el primero, se prepararon los instrumentos y se preparó el equipo para los pasos posteriores. En el segundo, la recolección se realizó considerando la captura de los conocimientos previos de los estudiantes mediante la aplicación de un cuestionario de encuesta y los informes de observación construidos a partir de la producción de blogs por parte de los estudiantes. En el tercero, el análisis de datos se realizó de forma interpretativa utilizando los procedimientos propuestos por el Análisis Textual Discursivo en cinco fases: unitarización, categorización, descripción, interpretación y argumentación. Se identificó que los estudiantes utilizaran el concepto de redes sociales como base para la construcción de blogs. Presentaron dificultades para operar su interfaz y comprender su dinámica, además de comprender metáforas como el concepto de dirección digital. Se pretende continuar la investigación ampliando el alcance de los estudiantes de este grupo de edad en contextos de creación y desarrollo de Blogs.

Palabras-clave: Tecnología educacional. Tecnología y didáctica. Enseñanza por computador. Aprendizaje. Enseñanza fundamental.

\section{INTRODUÇÃO}

Com o advento e a popularização das tecnologias digitais, surgiram novas maneiras de pensar, produzir, relacionar-se, aprender e ensinar. Valente (2007) afirma que as novas mídias são definidas como objetos culturais de distribuição e exibição de conteúdo que utilizam a tecnologia de computadores digitais, e deve ser cada vez mais incorporado à escola para que alunos e educadores possam aprender a ler, escrever e expressar-se por meio delas. Silva (2006) salienta que é fundamental que a escola, sendo principal agência de letramento, incorpore ao seu universo didático-metodológico práticas que promovam o domínio das tecnologias digitais. 
De acordo com Freire e Rodrigues (2010), desenvolver pesquisas na internet é uma atividade que não promove uma aprendizagem significativa, uma vez que os alunos apenas pesquisam, copiam, colam algum texto sobre o assunto solicitado. Valli (2015) também afirma que tal prática é muito comum e acontece sem a menor preocupação com a autoria, créditos e confiabilidade do material. Segundo Bierwagen (2011), embora os alunos não sejam leitores competentes para tal atividade, é comum que sequer recebam auxílio para selecionar, interpretar e relacionar informações.

O desenvolvimento de diferentes atividades fazendo uso de novos recursos digitais podem promover uma aprendizagem mais significativa para os alunos. Uma destas ferramentas é o Blog, que segundo Boeira (2008) trata-se de uma das TICs favorecidas pela disseminação da internet que ganhou destaque nestes últimos anos, sendo possível utilizar a ferramenta para tratar de praticamente qualquer assunto, inclusive temas educativos. De acordo com Santos, Grossi e Parreiras (2014), o termo Blog, simplificação de Weblog, refere-se a um registro feito na internet, servindo como uma agenda eletrônica ou um diário pessoal virtual. Apesar de seus benefícios, tem sido muito pouco explorado no Brasil quanto a seu potencial pedagógico: ainda que $47 \%$ dos alunos produzam imagens, textos ou vídeos para publicar na internet, apenas 3\% dos professores criam páginas na internet ou Blogs com seus alunos (CGI, 2018).

Conforme Almeida et al. (2015), o Blog é uma ferramenta de expressão de grande interesse quando produzido de maneira livre, quando os alunos não sentem algum tipo de pressão ou coerção advinda de alguma autoridade, como professores, por exemplo. Os estudantes têm a percepção de que a escola não interfere em sua “vida digital”. De acordo com Czerwinski e Cogo (2018), quando se trata do uso do Blog para atividades escolares, os alunos não divulgam ou promovem ampla interação com outros internautas, ao contrário da maneira que se expressam através de suas redes sociais. Almeida et al. (2015, p. 5) destaca que "muitos professores têm ignorado o fato de as novas mídias mudarem os modos de usar a linguagem" e que "os Blogs criados pelos professores são encarados como atividades escolares e, por isso, desinteressantes".

No entanto, criar um Blog não é uma tarefa fácil para os alunos quando inseridos no contexto educacional. Oliveira (2016) observou em sua pesquisa com alunos de $5^{\circ}$ ano do Ensino Fundamental I, que muitos estudantes apresentaram dificuldade em criar um Blog, sendo a possível causa sua inexperiência com a ferramenta. Pelos mesmos motivos, houve 
obstáculo na execução de enviar e receber e-mails. Em outro estudo com alunos desta mesma série escolar, Ono (2015) notou que alguns não sabiam sequer publicar ou responder a um comentário no Blog. É possível perceber uma variação do nível de letramento dos alunos; eles sabem manipular a interface, mas desconhecem conceitos básicos para a realização das tarefas solicitadas.

Bierwagen (2011) constatou em pesquisa desenvolvida com alunos do $7^{\circ}$ ano do Ensino Fundamental II que, em geral, não apresentam dificuldades em pesquisar o que lhes é solicitado, nem em fazer uploads de arquivos na internet. No entanto, a maior dificuldade dos alunos está em enviar links para Blogs. Portanto, tal letramento lança novos desafios educacionais no sentido de que alunos e educadores devem ter maior familiaridade com os recursos digitais, uma vez que fazer uso do dispositivo digital não promove, necessariamente, a construção de um significado que lhes permita utilizar as tecnologias em práticas pedagógicas.

De acordo com Silva (2013), a escola deve reformular certas práticas para se aproximar da realidade dos alunos na contemporaneidade, quando inseridos em contextos colaborativos e cooperativos. Para Cunha (2015, p.17), “cabe, portanto, à escola, tornar o ensino convidativo, atualizado considerando as necessidades e os interesses [...] de uma clientela infantil cada vez mais atualizada e mais exigente”. Segundo a pesquisa TIC Educação 2017, 92\% dos alunos diz que as atividades realizadas na internet fazem com que sintam mais vontade de aprender coisas novas, $70 \%$ deles acreditam que as atividades realizadas na internet ajudam a resolver dificuldades ou problemas que enfrentam na escola. Além disso, 52\% têm pretensão em trabalhar com tecnologia, computador e internet (CGI, 2018).

Silva (2006) mostra que o uso do Blog pode ser compreendido de maneira positiva pelos alunos, ao fazer com que se sintam sujeitos do próprio dizer, sendo interlocutores e promovendo uma leitura mais reflexiva e atrativa. Czerwinski e Cogo (2018) demonstram que através da publicação de comentários é possível estimular o uso do Blog como espaço de interação e construção do conhecimento.

Tendo em vista estas e outras possíveis barreiras e potencialidades para o uso do Blog com o objetivo educacional, apresenta-se a seguinte questão de pesquisa: quais são as dificuldades que alunos do Ensino Fundamental II apresentam para aprender a utilizar mídias digitais na construção de Blog? O objetivo da pesquisa é, portanto, analisar de que 
forma os alunos de $7^{\circ}$ ano de instituição de ensino particular utilizam as mídias digitais para a construção de Blog.

Classificada como exploratória qualitativa, a pesquisa, pautada na Análise Textual Discursiva (MORAES; GALIAZZI, 2016) foi aplicada com 23 alunos do $7^{\circ}$ ano do Ensino Fundamental. A coleta de dados se subdividiu em cinco fases com a aplicação de um questionário de sondagem e quatro relatórios de observação no momento da construção dos Blogs pelos sujeitos da pesquisa. A análise de dados ocorreu pela interpretação direta dos discursos escritos e falados dos alunos com base em sequência recursiva composta pela unitarização, categorização, descrição, interpretação e argumentação. Foram definidas duas categorias relacionadas às dificuldades dos alunos na construção dos Blogs e aos conceitos necessários para a compreensão de Blog.

Os alunos apresentaram inicialmente dificuldade para definir termos relacionados à incorporação, comentários e publicação em Blogs. Posteriormente, apresentaram dificuldade em compreender a dinâmica do Blog diferenciando-a da dinâmica comumente utilizada nas redes sociais, confundindo os conceitos de HTML (Hyper Text Markup Language) e link, bem como, dificuldades na compreensão de metáforas. Os resultados corroboram as informações de outros pesquisadores que se dedicaram a esse estudo, demonstrando que, apesar de os alunos dessa faixa etária estarem vivenciando um contexto tecnológico digital, apresentam dificuldades básicas de compreensão de uso de softwares na construção de Blogs e quando se tornam protagonistas no desenvolvimento de seus próprios materiais digitais.

\section{Referencial teórico}

De acordo com Baltazar e Aguaded (2005), a palavra Blog deriva da junção dos termos Web (rede) e log (registro, diário de bordo). Foi cunhada pela primeira vez por Jorn Barger, por volta de 1997, para se referir a uma página web onde se registrava um compilado de outros links. Entretanto, o conceito de Blog foi se modificando e atualmente é abordado de diferentes maneiras.

Blog pode ser compreendido a partir da perspectiva de ser um site (ESCOBAR, 2007), gênero discursivo (SOUZA, 2016), instrumento de expressão (AGUIAR, 2006) ou como um recurso pedagógico (SILVA, 2008). 
A partir de 1999, surgiram plataformas específicas para criação, edição e publicação de Blogs com baixo ou nenhum custo e sem a necessidade de conhecimento prévio da linguagem HTML (Hyper Text Markup Language), fazendo com que o número de Blogs crescesse muito devido a estas facilidades (BALTAZAR; AGUADED, 2005).

Atualmente, de acordo com o projeto Internet Live Stats, já existem mais de 1 bilhão e 700 milhões de Blogs criados, com um crescimento significativo a cada segundo. Uma das ferramentas de gerenciamento de Blog com maior destaque é o Blogger (http://www.blogger.com). Conforme explica Boeira (2008, p.3):

após criar o Blog pode-se criar e editar o post (que são cada um dos textos inseridos em um Blog). Para editar o post basta dominar as ferramentas de edição de texto. Os posts são apresentados de forma cronológica. É possível editar as postagens existentes em cada Blog e alterar, corrigir, acrescentar informações e excluir publicações. O Blogger oferece uma série de templates (formato da página). É possível alterar o template futuramente ou até criar um inteiramente novo caso o administrador domine a linguagem HTML.

Para Santos, Grossi e Parreiras (2014), um Blog, independentemente da plataforma onde é utilizado, tem dois componentes básicos: as postagens, que são pequenos textos, geralmente curtos, publicados pelos autores ou administradores do Blog; os comentários, que são as opiniões e contribuições dos leitores. Estes aspectos contribuem para que o Blog seja utilizado para expressar ideias, divulgar informações, comunicar experimentos, resultados e compartilhar conhecimentos. Segundo Escobar (2007), o Blog é caracterizado por ser um tipo específico de site, caracterizado pela presença de postagens, facilidade de criação e publicação das páginas e uso da ordem cronológica inversa (as postagens mais recentes aparecem no início da página).

Conforme Souza (2016), a estrutura do Blog permite abordar de maneira simples e direta, através do registro cronológico, frequente e imediato, os mais diversos temas através de textos, vídeos e imagens. Estas características fizeram com que o Blog fosse considerado e utilizado como diário ou agenda pessoal virtual desde seus primórdios, exigindo constantes atualizações por parte dos autores (SANTOS; GROSSI; PARREIRAS, 2014).

De acordo com Senra (2011), o Blog era utilizado principalmente por jovens que faziam seus diários pessoais virtuais. A partir da virada do século XX para o XXI, a ferramenta passou a ter uso mais diversificado, sendo mais frequentemente utilizada como meio de divulgação de diversos temas. Segundo Boeira (2008), esta estrutura permite o 
debate de ideias entre pessoas, independentemente da localização geográfica, com os mais diferentes pontos de vista e de forma assíncrona, promovendo a liberdade de expressão e a democratização das ideias, de informações e conhecimentos. De acordo com Aguiar (2006, p. 4-5), também faz surgir uma nova maneira de disseminação das notícias:

\begin{abstract}
Por se tratar de ferramentas comunicacionais simples, baratas e de fácil utilização os Blogs vêm se multiplicando na rede, assim como vêm se multiplicando, também, as formas de utilização e os objetivos deste tipo de páginas. O que nasceu como um "querido diário" virtual ou como uma espécie de guia de navegação ganha nova roupagem e começa a despontar como uma nova tendência jornalística. Além de divulgar informações e desabafos do autor, alguns Blogs assumem um caráter informativo e tratam de política, economia, esporte, além, é claro, de trazer as considerações, críticas e opiniões do autor sobre esses assuntos. Debates, divergências de opiniões, interpretações variadas têm, nesse meio, espaço garantido.
\end{abstract}

Embora a autora demonstre a nova tendência de produção jornalística, faz a ressalva de que não acredita que a produção de Blogs venha a substituir a mídia convencional, porém, funciona de maneira complementar e aproxima jornalistas e leitores, veículo e público (AGUIAR, 2006).

De acordo com Senra (2011), a interatividade é um recurso muito explorado nos Blogs, e a partir disso, redes colaborativas de aprendizagem se formam. Conforme Boeira (2008, p.3) "professores e alunos de todos os níveis de ensino descobrem na criação de Blogs uma outra forma de aprender, de ensinar, de informar, de conhecer, de compartilhar, de publicar, de comunicar".

De acordo com Lais (2016), o avanço tecnológico reflete diretamente sobre as subjetividades e, consequentemente, causa mudanças na leitura e na escrita. De acordo com a autora, surge uma forma linguística específica e híbrida no meio digital, exigindo uma leitura mais crítica e uma produção de texto mais contextualizada. Sendo assim, o Blog seria considerado um gênero digital. De acordo com Silva (2008), geralmente as postagens dos Blogs são curtas, mas não há uma padronização sobre o emprego da linguagem e consenso sobre a formalidade da escrita.

Assim sendo, conforme destaca Souza (2016), isso faz com que surjam novas necessidades pedagógicas e de aprofundamento dos estudos relativos aos letramentos no ambiente educacional, mediante as novas formas de comunicação exigidas na sociedade em rede, ciberespaço e cibercultura. De acordo com Boeira (2008), o uso de Blogs na 
educação é um tema que se impõe pela atualidade, e é um assunto que não pode ser simplesmente ignorado pela escola.

Para Santos, Grossi e Parreiras (2014), o perfil dinâmico do Blog faz com que seja uma ferramenta com potencial para promover a dinamização e facilitar a relação entre ensino, aprendizagem e interação social. Através de simples comentários ou até a inserção de artigos, imagens ou vídeos, a ferramenta pode promover a integração dos alunos, professores, familiares, e toda a comunidade escolar utilizando processos de inclusão sociodigital. De acordo com Silva (2008, p.5), “o Blog educacional pode ser considerado como um espaço eletrônico individual ou coletivo próprio para se partilhar informações, ideias, opiniões, materiais e referências".

Silva (2008) ressalta a importância do papel do professor em demonstrar os diferentes estilos e as variações de fala/escrita ao usar o Blog, para que assim os alunos desenvolvam autonomia e tenham condições de ler e produzir textos de maneira mais adequada do ponto de vista profissional, com compreensão crítica e conteúdo relevantes. O Blog oferece ao professor facilidade em fazer intervenções, corrigindo e orientando os alunos sem ser limitado ao tempo imposto pela sala de aula, ao passo que o aluno também pode realizar suas atividades no seu próprio ritmo e tem a possibilidade de exercer sua liberdade de expressão (SENRI, 2011).

Constituindo o Blog como recurso de apoio à aprendizagem e espaço de criação coletiva de estudantes e professores, a escola cumpre seu papel em preparar o aluno para os desafios impostos pela sociedade, promovendo o desenvolvimento da autonomia dos estudantes para que sejam capazes de transformar esta realidade que ora se apresenta através do uso das TICS (SENRI, 2011).

Baltazar e Aguaded (2005), em seu estudo com Blogs na educação, classificou-os em três categorias: os Blogs de professores, os Blogs de alunos, e os Blogs de disciplina. Os Blogs de professores são aqueles utilizados como diário de classe, onde são disponibilizadas informações sobre as aulas, programação, material complementar, resumos, bibliografia, entre outros (BALTAZAR; AGUADED, 2005). Este tipo de Blog é útil para a organização da turma e consulta de materiais, mas promove pouco dinamismo e comunicação.

Já os Blogs de alunos, foram agrupados de acordo com seus diferentes usos, sendo eles os Blogs criados para serem avaliados, como um trabalho ou parte da avaliação de uma 
disciplina; os Blogs que funcionam como repositórios de links para artigos, Blogs, sites, estudos e de materiais considerados importantes; os Blogs de colegas de escola, que podem ser criados em grupo para que possam se comunicar, trocar informações, estudar em conjunto, esclarecer dúvidas, dentre outros; os Blogs individuais ou coletivos para a publicação de trabalhos.

O terceiro tipo, os Blogs de disciplina, são aqueles mantidos por professores e alunos de forma colaborativa. Neste tipo de Blog, todos podem participar, escrever postagens e comentários, colocar questões, publicar trabalhos, entre outros. Esta categoria de Blog é a que apresenta as maiores potencialidades no processo de ensinoaprendizagem devido a sua natureza dinâmica e interativa (BALTAZAR; AGUADED, 2005).

\section{Metodologia}

A pesquisa classificada como exploratória qualitativa com coleta e análise pautadas na Análise Textual Discursiva (MORAES; GALIAZZI, 2016) foi aplicada com 23 alunos que cursavam $07^{\circ}$ ano do Ensino Fundamental em 2019 em Colégio Particular no município de Fortaleza, CE. Apresentam idades entre 11 e 13 anos, sendo 14 (60,9\%) alunos do gênero masculino, e $9(39,1 \%)$ do gênero feminino. 20 alunos estudam no colégio desde 2018, e outros 3 são novatos, tendo ingressado na escola no mesmo ano letivo em que ocorre esta pesquisa.

O Colégio funciona desde o ano de 2003 atendendo alunos do Ensino Fundamental II ( $6^{\circ}$ ao $9^{\circ}$ ano) dentro de uma proposta pedagógica socioconstrutivista. Segundo sua proposta político pedagógica, o colégio busca desenvolver, além da formação acadêmica, competências vinculadas à capacidade de trabalho em grupo, liderança, flexibilidade, criatividade e autonomia.

Os alunos utilizam a internet majoritariamente através do smartphone (87\%) e do computador (82,6\%). Utilizam estes dispositivos constantemente (mais do que 3 vezes ao dia) e principalmente em atividades de entretenimento, como assistir ao material disponível no YouTube $(60,9 \%)$ e participar de jogos on-line (47,8\%). A maioria $(69,9 \%)$ se comunica através do mensageiro instantâneo WhatsApp.

Os pais dos alunos participantes assinaram um termo de Consentimento Livre e Esclarecido, autorizando a participação de seus filhos(as) na pesquisa, assim como, o 
Colégio também atribuiu consentimento para que se tornasse um lócus de coleta de dados. A pesquisa foi aceita pelo Comitê de Ética em Pesquisa vinculado à Universidade Federal do Ceará.

A pesquisa se subdividiu em três etapas: planejamento, coleta e análise de dados. Na primeira, foram elaborados os instrumentos de coleta e análise de dados da pesquisa, além da preparação dos equipamentos para a construção do Blog pelos alunos.

$\mathrm{Na}$ segunda, a coleta se subdividiu em cinco fases utilizando os seguintes instrumentos: um questionário de sondagem para captação dos conhecimentos prévios dos alunos sobre os conceitos vinculados ao conteúdo de Blog e quatro relatórios de observação, utilizados no momento em que os alunos se encontravam em processo de desenvolvimento de seus Blogs em grupo.

Na primeira fase, ocorrida em 24 de abril de 2019, o questionário de sondagem foi aplicado com a turma, individualmente, contendo 12 questões, dentre elas a solicitação da definição de blog, postagem, link, incorporação, comentário e publicação de textos em blogs.

A partir da segunda fase da coleta, os dados foram registrados em diário de campo para desenvolvimento posterior de relatório com informações sobre data, hora, local, atividades desenvolvidas pelos alunos, descrição das ações de cada grupo durante a atividade, evidências das dificuldades encontradas pelos alunos e resultados obtidos após as atividades dentro do Blog construído pelos sete (7) grupos pré-definidos. Todas as atividades foram desenvolvidas no laboratório de informática do Colégio sob a regência dos professores de inglês e de informática com escrita de texto na língua inglesa.

Na segunda fase, ocorrida em 29 de abril de 2019, os grupos iniciaram a construção de um Blog e fizeram a primeira postagem vinculada ao capítulo "People and Places", do livro paradidático Malala (BEDDAL, 2018). Na terceira fase, ocorrida em 08 de maio de 2019, os grupos criaram a segunda postagem, escrevendo um parecer sobre a compreensão que apresentavam dos capítulos lidos do livro paradidático, com um parágrafo escrito por cada integrante do grupo. Na quarta fase, ocorrida em 15 de maio de 2019, os grupos incorporaram em seus respectivos Blogs um vídeo do YouTube relacionado a uma personalidade pública, trazendo sua história e seus feitos mediante contribuições à sociedade; o link do Blog foi compartilhado com os demais colegas via Google Classroom. Na quinta fase, ocorrida em 22 de maio de 2019, os grupos fizeram comentários nos Blogs 
dos demais grupos e enviaram uma nova postagem para seu próprio Blog a respeito da opinião pessoal sobre um dos capítulos do livro paradidático adotado, de livre escolha.

A análise de dados aconteceu por meio da comparação dos resultados obtidos nos instrumentos de coleta diante da interpretação dos discursos escritos e falados dos alunos. Para auxiliar o processo, utilizaram-se os procedimentos propostos pela Análise Textual Discursiva (MORAES; GALIAZZI, 2016). Diante de um processo organizado para a compreensão do fenômeno estudado e a busca dos elementos emergentes da pesquisa utilizou-se uma sequência recursiva composta por cinco (5) fases: unitarização, categorização, descrição, interpretação e argumentação.

$\mathrm{Na}$ fase da unitarização foram definidas as unidades de análise, com seleção e definição do corpus utilizado, iniciando-se a desmontagem dos textos. As unidades de análise foram codificadas e definidas, utilizando-se como base os aspectos emergentes das leituras e releituras dos textos selecionados. Posteriormente, as unidades foram reescritas com atribuição de um título, representando sua ideia central.

$\mathrm{Na}$ fase da categorização, agruparam-se elementos semelhantes, por meio da comparação das unidades de análise. Utilizou-se um método indutivo, construindo-se as categorias emergentes a partir das informações captadas do corpus. Neste momento inicial, as unidades de análise foram comparadas e agrupadas para atribuição de significado. Com isso, as categorias foram criadas, definidas e nomeadas.

$\mathrm{Na}$ fase da descrição apresentaram-se elementos emergentes dos textos analisados e representados pelas categorias construídas. Realizaram-se novas leituras e interpretação direta dos textos, com utilização de recortes produzidos pelos sujeitos da pesquisa. Na fase da interpretação, desenvolveu-se uma leitura teórica dos fatos empíricos de forma profunda e complexa, estabelecendo-se uma relação entre as descrições interpretativas e os aspectos teóricos que compõem a pesquisa bibliográfica.

$\mathrm{Na}$ fase da argumentação, apresentaram-se afirmações teóricas emergentes do processo de análise com a elaboração de um metatexto de caráter descritivo, formado por elementos introdutórios, pela produção de uma argumentação centralizadora que explica o todo a partir das relações dos argumentos produzidos para as categorias e por um fechamento que torne o texto o mais claro e preciso possível.

Foram definidas duas categorias. A primeira diz respeito às dificuldades que os alunos apresentam para aprender a utilizar as mídias digitais na construção do Blog. A 
segunda se relaciona às transformações vinculadas aos conceitos de blog, postagem e link, à incorporação de texto digital e à interação no meio digital, considerando-se o uso de comentários e publicação de textos em Blog.

\section{Resultados e discussão}

Os dados são apresentados de forma a preservar a identidade dos sujeitos da pesquisa de maneira organizada. Sendo assim, quando forem representados de forma individual são denominados A1 até A23; quando forem representados no formato de grupo são denominados G1 até G7.

\section{Questionário de Sondagem}

Quanto à compreensão do conceito de Blog, dos 23 alunos, 6 vincularam-no à ideia de diário pessoal virtual, onde se compartilham detalhes da vida pessoal do indivíduo: "Um site que a pessoa posta fotos, textos e coisas sobre sua vida" (A5). Outros 6 alunos vincularam-no a um meio de expressão, onde há discussão e compartilhamento de ideias: "Um site onde você pode compartilhar suas ideias" (A18). Outros 5 alunos responderam de forma mais generalizada, de tal maneira que não foi possível vincular a uma ideia precisa sobre Blog: "É um site criado por você" (A23). Os 6 alunos restantes responderam "não sei" (A2) ou "não sei explicar" (A19).

Assim como há diferenças entre as ideias dos alunos na compreensão do que é um Blog, diversos autores adotam abordagens distintas para explicar o conceito. A definição apresentada por Santos, Grossi e Parreiras (2014) se refere à palavra Blog como um registro feito na internet, servindo como uma agenda eletrônica ou um diário pessoal virtual, corroborando as ideias de parte do grupo de alunos.

Escobar (2007) afirma que Blog pode ser considerado um tipo específico de site, caracterizado pela presença de postagens, facilidade de criação e publicação das páginas e uso da ordem cronológica inversa, corroborando em parte as ideias de outro grupo de alunos, principalmente no que diz respeito ao uso do termo "site".

Apesar de não serem antagônicas, estas abordagens são coerentes com a compreensão mais abrangente apresentada por Souza (2016, p. 22) “Blog é um espaço na 
web cuja estrutura permite, através de uma forma simples e direta, o registro cronológico, frequente e imediato de opiniões, emoções, imagens, notícias ou qualquer outro tipo de conteúdo". Nesse sentido, os alunos não expressaram a importância do tempo e de sua correlação com a ideia de Blog destacada pelos autores.

É relevante perceber ainda que ao utilizarem os termos "vídeo" ou "gravar" se aproximam do conceito de Vlog definido por Morais (2017) como uma abreviação do termo videolog (vídeo+Blog), uma variação do conceito de Blog.

Quanto à compreensão do conceito de postagem, os alunos não especificaram a ideia do objeto a ser enviado, mas ao local para onde poderiam mandar as mensagens. Postar estaria vinculado, portanto, ao envio de "algo" para blog, redes sociais ou internet. Dos 23 alunos, 2 vincularam a postagem ao Blog: “Eu acho que postagem é colocar algo em seu Blog e complementá-lo" (A19). Outros 5 alunos à ideia de redes sociais: "Algo que qualquer pessoa possa expor nas redes sociais" (A7). A maior parte dos alunos, 14 ao todo, pensaram de forma mais ampla, associando a postagem à internet: "é quando postamos alguma foto massa do que estamos fazendo. Exemplo: posto foto tomando sorvete" (A22). Do total, apenas 2 alunos afirmaram não saber o que significava postagem.

Santos, Grossi e Parreiras (2014) explicam que as unidades básicas de um Blog são as postagens e os comentários, elementos-chave das redes sociais. Neste sentido, é possível perceber que os alunos associam a postagem mais às redes sociais do que à ideia de Blog. De qualquer maneira, a associação da ideia de postagem ao local onde a informação será divulgada denota que os alunos estão próximos das ideias dos autores uma vez que postagem expressa as informações a serem comunicadas nesses espaços como experimentos, resultados ou apenas compartilhamento de conhecimentos.

Quanto à compreensão do conceito de link, os alunos utilizaram termos com diferentes significados. Dos 23 alunos, 8 relacionaram link com código: "É um código/conjunto de palavras que te leva a determinado site, imagem, vídeo, etc." (A2). Outros 3 alunos relacionaram à ideia de endereço: “É um endereço eletrônico que te leva diretamente a um site ou post específico" (A4). Outros 2 alunos à ideia de atalho: "É um atalho para entrar em sites" (A16). Outros 8 alunos trouxeram respostas variadas: "Quando repostamos algo de outro site" (A6). E 2 alunos não souberam responder.

De acordo com o dicionário Priberam (2017, p. 96), link significa "ligação que consiste num ícone ou numa sequência de texto que, quando ativados, permitem o acesso 
à informação eletrônica noutra localização (documento, arquivo, página da Internet, etc.)". Enquanto o link informa o endereço das páginas web, estas são compostas basicamente por documentos em HTML (Linguagem de Marcação de Hipertexto, em português). Os navegadores de internet oferecem maneiras de consultar o código daquilo que foi carregado e processado.

Contudo, alguns alunos acreditam que o endereço da página é o que define sua construção, considerando-se que 8 alunos utilizaram o termo "código" para descrever link, com definições que se encaixam no significado do que é código HTML. O aluno A12, descreveu link como "Um código que incorpora páginas", enquanto Ag respondeu “É o código do site". Foram poucos os alunos que se aproximaram da definição de link trazida pelo dicionário, vinculando-a à ideia de endereço e de atalho para acesso a informações em outro local da internet.

Em relação à compreensão do conceito de incorporação, somente 2 respostas foram explicitadas: "seguir um personagem" (A6) e "significa fazer outro tipo de Blog" (A11). Os outros 21 alunos responderam não saber o que é incorporação.

Incorporar, no contexto do Blog, é uma maneira onde o autor pode editar a formatação HMTL de sua postagem ou também inserir códigos de conteúdo externo como, por exemplo, vídeos da plataforma YouTube. Para Santos, Grossi e Parreiras (2014), é por meio da simples incorporação de artigos, imagens ou vídeos que se promove a integração entre alunos, professores, familiares por meio de processos de inclusão sociodigital. O fato de os alunos não saberem definir esse aspecto vinculado ao Blog pode denotar que não conhecem essa faceta desse tipo de recurso digital, ou que preferem utilizá-lo para compartilhamento de informações dentro de sua comunidade particular de colegas de sua idade. Essas inferências corroboram as ideias de Silva (2008, p.5) ao afirmar que, "o Blog educacional pode ser considerado como um espaço eletrônico individual ou coletivo próprio para se partilhar informações, ideias, opiniões, materiais e referências".

Em relação à compreensão de como fazer comentários em um Blog houve quatro tipos de respostas. Dos 23 alunos, 9 trouxeram respostas vinculadas a um aspecto mais técnico descrevendo alguma ação executada com uma finalidade determinada: "Eu acho que você vai até o final do Blog e vai ter uma caixinha com uma opção comentar" (A18). Somente 3 alunos relacionaram os comentários em um Blog aos aspectos sociais como etiqueta, reflexão e empatia: "Ser educada e pensar como a pessoa que ler seu comentário 
vai se sentir" (A5). Outros 2 alunos trouxeram ambos os aspectos, aqueles mais técnicos ao mesmo tempo que trataram dos aspectos sociais: "Clicar em comentários e digitar o que você pensa sobre o assunto" (A8). Os 9 alunos restantes não souberam responder.

Em pesquisa com alunos do Ensino Fundamental, Ono (2015) constatou que poucos deles sabiam publicar ou responder a um comentário em Blogs. Portanto, a utilização do Blog como uma ferramenta de interação digital no contexto educativo tende a ser um desafio. Parte dos alunos associaram a ideia de comentário ao sentido original da palavra vinculada à ideia de conversa e discussão entre pessoas. Por outro lado, ocorreu uma conexão entre a ideia de comentário com sua função nas redes sociais, reforçando o quanto a conexão entre os conceitos de Blog e rede social é relevante.

Quanto à compreensão da publicação em Blog, mais uma vez trouxeram 4 formas de pensar diferentes. Dos 23 alunos, 9 vincularam a publicação a aspectos mais técnicos, descrevendo o tipo de conteúdo citando seu suporte, texto, áudio, vídeo, entre outros: “Imagens, links e vídeos, também textos" (A21). Outros 8 alunos vincularam a publicação em Blog com uma descrição de acordo com a finalidade de comunicação e expressão: "Tudo que você acha interessante para outras pessoas" (A20). Outros 5 alunos relacionaram a ideias mais genéricas, trazendo descrições como "tudo" ou "qualquer coisa": "Tudo o que você quiser" (A11). Apenas 1 aluno afirmou não saber sobre o assunto.

De acordo com Baltazar e Aguaded (2005), os Blogs mantidos de maneira colaborativa apresentam grandes potencialidades no processo de ensino-aprendizagem devido a sua natureza dinâmica e interativa. A publicação, segundo os autores, é o momento de revelação das informações para o mundo que vai além dos aspectos técnicos, promovendo uma interação do sujeito criador do Blog com outros que terão a oportunidade de conhecer o que está exposto na internet.

Dessa forma, os alunos se mostraram mais conectados ora às ideias técnicas, ora às ideias genéricas, denotando ter pouca consciência sobre esse momento de interação com os outros a partir de um compartilhamento real de seus materiais.

Sendo assim, foi percebido por meio da aplicação do Questionário de Sondagem que os alunos apresentam conceitos genéricos sobre os elementos que compõem um Blog, denotando pouca intimidade com seu uso no cotidiano escolar. É perceptível também que os conceitos de Blog e de rede sociais estão conectados, interligados na estrutura cognitiva dos alunos. Para muitos deles, o Blog é uma rede social. Ambas as plataformas são 
semelhantes e a principal diferença entre elas é a forma de produção e publicação do conteúdo, uma vez que as redes sociais exigem um padrão específico de mídia e não permitem personalização da formatação do texto.

A utilização do Blog pode permitir uma variedade maior para a produção de conteúdo quando se trata do formato eletrônico, contribuindo para a alfabetização digital do aluno. A forma de organização e documentação também promove um espaço de mais autonomia e personalização, não dependendo apenas da timeline (forma gráfica e linear para representar uma sequência de eventos em ordem cronológica) para sua divulgação.

\section{Desenvolvimento dos Blogs}

São apresentados, neste subcapítulo, inicialmente, uma descrição dos resultados obtidos com as fases dois a cinco da coleta de dados, evidenciando-se as categorias, com discussão pautada no referencial teórico utilizado na pesquisa.

Após o primeiro login na plataforma Blogger, os grupos $G 1, G 3$, G5 e $G 6$ encontraram dificuldades por não saberem se deveriam prosseguir utilizando o nome do grupo ou se utilizariam um nome de representação de equipe ou do responsável pela conta.

Para definir o nome do Blog e sua URL (Uniform Resource Locator) personalizada os grupos G2, G3 e G6 tiveram dificuldades por não saberem que caracteres especiais e espaço não devem ser utilizados para definir um endereço na internet. A própria plataforma apresentou feedback de erro, mas ainda assim pediram ajuda para o professor para conseguirem prosseguir. O G5 se deparou com este mesmo tipo de problema, contudo, isto aconteceu por tentarem utilizar um endereço residencial de um dos membros para definir o endereço do Blog.

O G6 não encontrou problemas, mas demorou para definir o grupo, pois não chegava a um consenso. Assim como aconteceu no G1, os alunos do G6 se sentiram inseguros quanto à escolha do tema do Blog, pois não sabiam se era possível alterá-lo posteriormente. O G7 não apresentou nenhuma dúvida nesta etapa. Seguem as URLs dos Blogs criados por cada grupo:

- G1 - https://theextraordinarymalala.Blogspot.com/

- G2 - https://jubsov.Blogspot.com/

- G3-https://glaja.Blogspot.com/ 
- G4 - https://malala07.Blogspot.com/

- G5 - https://nobeldapa.Blogspot.com/

- G6 - https://hdjrl.Blogspot.com/

- G7 - https://segueacalldamalala1337.Blogspot.com/

Em relação à primeira postagem no Blog, vinculada à segunda fase da coleta, os grupos G1 e G4 solicitaram ajuda, e apenas os grupos G2 e G3 realmente publicaram as postagens em seus Blogs.

Para a realização da segunda postagem, vinculada à terceira fase da coleta, todos os grupos utilizaram recursos de edição de texto como Microsoft Office Word e Google Docs, recursos com os quais estavam mais familiarizados. O G1 teve dificuldade de recuperar o acesso ao Blog criado na aula anterior. E apenas o $\mathrm{G}_{4}$ concluiu a atividade. Os demais grupos ficaram sem enviar postagens para seus respectivos Blogs.

Para a incorporação do vídeo nos Blogs, vinculada à quarta fase da coleta, os grupos G1 e G4 não se lembravam como configurar o editor do Blog no modo de escrita HTML e os grupos G2 e G5 não identificaram a opção de compartilhar na interface do YouTube. O G5 enfrentou problemas técnicos com o computador e o G6 teve dificuldades para realizar o comando de copiar e colar.

O G4 se dividiu e, enquanto metade do grupo escolhia o vídeo e fazia a incorporação do conteúdo, o restante escreveu um pequeno texto para complementar o conteúdo da postagem. Sendo assim, completou as tarefas com maior agilidade.

Quanto ao envio do link, ainda na quarta fase da coleta, o $G_{3}$ publicou o link do editor do Blogger, o G6 enviou o código de incorporação do vídeo do YouTube e, portanto, estavam incorretos. O G4 enviou a URL da página inicial do Blog ao invés do link da publicação específica (realizou a atividade de maneira parcialmente correta) e o G7 conseguiu completar a tarefa de acordo com o que foi solicitado. Todas as equipes fizeram a publicação de acordo com os requisitos básicos solicitado, mas, os grupos $\mathrm{G}_{1}, \mathrm{G}_{2}$ e $\mathrm{G} 5$ não fizeram o envio do link como solicitado.

$\mathrm{Na}$ atividade vinculada ao comentário nos Blogs dos colegas, vinculada à quinta fase da coleta, nenhum grupo solicitou ajuda. Entretanto, os grupos $\mathrm{G}_{2}, \mathrm{G}_{4}$ e $\mathrm{G} 5$ não realizaram esta atividade e os grupos $\mathrm{G} 1, \mathrm{G} 3$ e $\mathrm{G} 6$ utilizaram uma mesma conta para fazê-lo, ao invés de utilizar logins individuais. 
Os grupos G5 e G6 disseram ao professor que não estavam tendo dificuldades, mas não postaram nenhum comentário e nem compartilharam acesso entre os membros das equipes. Os grupos $\mathrm{G}_{1}$ e G7 fizeram o compartilhamento de acesso entre diferentes contas, mas publicaram todos os comentários em uma única postagem. O G4 realizou uma postagem diferente para cada membro, mas não compartilhou o acesso e utilizou uma mesma conta para a publicação. Nenhum grupo realizou as atividades de acordo com o que foi proposto na tarefa.

De maneira resumida, os grupos apresentaram as seguintes dificuldades para desenvolver as atividades nos respectivos Blogs:

- Apresentar dúvida entre nome de equipe e nome de usuário - G2, G3, G4, G5, G6;

- Inserir imagem - $\mathrm{G}_{1}, \mathrm{G}_{4}, \mathrm{G} 5$;

- Publicar a primeira postagem - $\mathrm{G}_{1}, \mathrm{G}_{2}, \mathrm{G}_{3}, \mathrm{G}_{5}, \mathrm{G} 6, \mathrm{G} 7$;

- Enviar o link da postagem - $\mathrm{G}_{1}, \mathrm{G}_{2}, \mathrm{G}_{3}, \mathrm{G}_{4}, \mathrm{G}_{5}$;

- Alternar entre modo Escrever e Incorporar no editor do Blogger - G1, G7;

- Obter código de incorporação - G2, G5;

- Postar comentário final - G5, G6.

Oliveira (2016) e Ono (2015) demonstraram em suas pesquisas com alunos de $5^{\circ}$ ano do Ensino Fundamental que existem variações no nível de aptidão apresentada pelos alunos quanto ao uso de tecnologias relacionadas ao Blog. No caso da presente pesquisa, nenhum dos grupos realizou todas as atividades de acordo com o que foi solicitado. Parte da dificuldade advém do uso da própria plataforma. Oliveira (2016) observou que os alunos não sabem criar um Blog de forma independente, diante da inexperiência que apresentam com a ferramenta, corroborando os resultados obtidos até então.

Apesar de Bissolotti, Gonçalves e Pereira (2015) explicarem sobre a necessidade de interfaces projetadas para o público infanto-juvenil atentarem para foco no entretenimento, apelo visual, usabilidade, conteúdo adaptado à idade e o incentivo à aprendizagem, a plataforma Blogger não tem esse objetivo de uso específico o que pode agravar a dificuldade que os grupos apresentaram para o desenvolvimento das atividades propostas.

Além disso, considerando-se que alunos dessa faixa etária tendem a ser literais quando decodificam informações (BISSOLOTTI; GONÇALVES; PEREIRA, 2015), pode 
justificar a dificuldade de compreensão em relação ao compartilhamento de acesso do Blog entre os integrantes do grupo. Esse aspecto também afetou o uso de diferentes perfis para a publicação de comentários.

Compreende-se que, devido ao uso mais habitual das redes sociais, os alunos tenham maior familiaridade com seus acessos diretamente conectados à página da respectiva rede social. No caso do Blog que apresenta uma lógica diferente, os alunos apresentaram dificuldades para criar e acessar o Blog, desencadeando problemas diversos, dentre eles, a limitação da compreensão de que os alunos poderiam construir estruturas em um objeto digital coletivo. Nesse sentido, utilizar a metáfora da rede social para introduzir o conceito de Blog, pode paradoxalmente causar empecilhos e fazer com que se confundam no uso dos dois tipos de ferramentas digitais.

No entanto, para os alunos que têm menos contato com as redes sociais e com as tecnologias digitais em seu cotidiano, o problema se apresentou de outra maneira. Além de não conseguirem finalizar as atividades propostas, ao definirem a URL do Blog, optaram por inserir o endereço residencial, denotando a pouca familiaridade com o conceito de endereço do ponto de vista virtual. Esse aspecto evidencia a inclinação à literalidade como apresentado por Bissolotti, Gonçalves e Pereira (2015).

Bierwagen (2011) em sua pesquisa com alunos do $7^{\circ}$ ano do Ensino Fundamental observou que estes não apresentavam dificuldades em pesquisar o que foi solicitado, nem em fazer upload do arquivo no Google Docs, mas tinham muita dificuldade em fazer a postagem de um link. Na presente pesquisa um dos grupos apresentou dificuldade em copiar e colar links para o Blog, contrariando sobretudo as pesquisas apresentadas por Freire e Rodrigues (2010) e Valli (2015) ao retratarem que essa seja uma prática comum nas escolas brasileiras.

No entanto, é notória a despreocupação dos alunos ao copiar e colar links nos seus respectivos Blogs, principalmente ao se notar que, em alguns grupos, os links enviados direcionavam para locais divergentes na internet. Nesse sentido, os resultados obtidos convergem para os achados de Valli (2015) ao caracterizar a problemática da autoria, dos créditos e da confiabilidade do material quando os alunos necessitam transferir links de um local para outro dentro da grande rede.

Além disso, os alunos tiveram dificuldades em relação à diferenciação de código e link, uma vez que um dos grupos enviou o código HTML de um site ao invés de seu link em 
uma das postagens do Blog. Ainda não ficou esclarecido para os alunos essas diferenças conceituais, faltando a construção de um letramento que os conduza a ações adequadas dentro do desenvolvimento de uma atividade comum em contextos de construção de Blogs.

Em relação à incorporação de conteúdos nos Blogs via HTML, todos os grupos desempenharam de maneira satisfatória mesmo não sabendo dizer, no questionário de sondagem, o que significava incorporação. É importante ressaltar que esta foi uma das poucas atividades que todos os grupos executaram corretamente.

O fato de terem utilizado um único perfil desde o início comprometeu as atividades que promoveriam a interação no meio digital. Mesmo que nenhum grupo tenha solicitado ajuda para fazer comentários, nenhum deles completou a tarefa utilizando perfis individuais. O mesmo aconteceu com as publicações. Esse fenômeno se assemelha àquele verificado por Ono (2015). Em sua pesquisa, os estudantes não sabiam publicar ou responder a um comentário no Blog.

No entanto, Czerwinski e Cogo (2018) demonstram que através da publicação de comentários é possível estimular o uso do Blog como espaço de interação e construção do conhecimento. Percebe-se, portanto, que há necessidade de se investir no desenvolvimento de Blogs com alunos dessa faixa etária estimulando, sobretudo, as publicações e os comentários no sentido de promover uma interação construída com os alunos, diante de suas necessidades de aprendizagem.

O segundo desafio surge devido à diferença estrutural do Blog com as demais redes sociais, sobretudo ao se utilizar a plataforma Blogger. Os alunos estão acostumados a criar uma conta que é automaticamente correspondente a um perfil. No Blog, esse aspecto se apresenta de forma diferente. É importante explorar cautelosamente esta ideia no sentido de conscientizá-los das potencialidades da construção de um espaço coletivo virtual e dos motivos da importância para o desenvolvimento de suas habilidades digitais e colaborativas.

\section{CONSIDERAÇÕES FINAIS}

Considerando-se o problema das possíveis barreiras e potencialidades não exploradas para o uso do Blog no contexto educativo, o objetivo da pesquisa foi analisar 
de que forma os alunos de $7^{\circ}$ ano de instituição de ensino particular utilizam as mídias digitais para a construção de Blog.

Percebeu-se que os alunos têm pouco contato com o uso de Blog, ainda que saibam o seu conceito na forma abstrata. Eles consideram que o Blog seja similar às redes sociais e apresentem as mesmas estruturas. Entretanto, recursos como a edição de HTML e a publicação de conteúdos são elementos que ainda não conseguem utilizar com facilidade.

Inicialmente, no questionário de sondagem, as maiores dificuldades apresentadas foram definir o significado de incorporar, explicar como fazer comentários em um Blog e dizer como publicar algum conteúdo na internet.

Quando desenvolveram os Blogs, os grupos tiveram dificuldades em operar sua interface e entender sua dinâmica, e por isso não compartilharam acesso com os colegas para que a construção fosse efetivamente colaborativa no contexto virtual. Como a colaboração entre os grupos ocorreu em maior parte presencialmente, no espaço da sala de aula, houve alguns problemas de cooperação a respeito da autogestão dos grupos e os diferentes níveis de aptidão tecnológica digital. Além disso, notou-se que, na prática, confundem os conceitos de HTML e link, com dificuldades na compreensão de metáforas, como o episódio relacionado ao endereço virtual dos Blogs criados.

Dessa forma, percebe-se a necessidade de conscientização dos alunos sobre os benefícios e os motivos do uso desse tipo de ferramenta digital, além de proporcionar tempo adequado para que explorem e pratiquem as habilidades adquiridas. Assim, os alunos podem aprender mais significativamente, encontrando um sentido para sua produção intelectual aliada ao desenvolvimento de tecnologia digital na prática.

Recomenda-se que os alunos dessa faixa etária tenham mais experiências de construção de Blogs em diferentes contextos escolares, não só para utilização nas disciplinas curriculares, mas também, diante de desafios e necessidades trazidos pelos próprios alunos ou criados pela escola em que os alunos viabilizem soluções proporcionando o desenvolvimento da criatividade e da autonomia.

Em seu cotidiano, a maioria dos alunos já faz uso de outras redes sociais para se expressar e consumir conteúdos na internet. Entretanto, quando comparado a estas plataformas, o Blog permite maior liberdade para a construção de produtos tecnológicos e aumenta as possibilidades de expressão. Para isso, é necessário entender suas 
funcionalidades mais específicas (edição de HTML) e disseminar o conteúdo produzido (através de links) nestas outras redes.

Por se tratar de uma pesquisa exploratória com uma quantidade reduzida de alunos e em escola particular de ensino, a pesquisa não permite generalizações, limita-se a descrever os dados obtidos de um grupo seleto com análise interpretativa pautada no discurso dos sujeitos da pesquisa. Sendo assim, pretende-se continuar a investigação com um corpo maior de alunos dessa faixa etária, contemplando-se um público também de escolas públicas em diferentes contextos de criação e de desenvolvimento de Blogs.

\section{REFERÊNCIAS}

AGUIAR, Kátia Fonseca. Blog-jornalismo: interatividade e construção coletiva da informação. Biblioteca on-line de Ciências da Comunicação (BOCC). 2006. Disponível em: < http://www.bocc.ubi.pt/pag/aguiar-katia-blog-jornalismo.pdf >. Acesso em: 30 nov. 2019.

ALMEIDA, Jaqueline Maria de; CASTELANO, Karina Lôbo; SANTO, Janete Araci do Espírito; SOUZA, Carlos Henrique Medeiros de; LUQUETTI, Eliana Crispim França. Uso do Blog na escola: recurso didático ou objeto de divulgação? InterSciencePlace, v. 1, n. 22, jul./set. 2012. p. 1-15.

BALTAZAR, Neusa; AGUADED, Ignacio. WeBlogs como recurso tecnológico numa nova educação. In: ASSOCIAÇÃO PORTUGUESA DE CIÊNCIAS DA COMUNICAÇÃO, 4, 2005, Aveiro. Livro de Actas - $4^{\circ}$ SOPCOM, p. 1655 -1665.

BEDDAL, Fiona. Malala. São Paulo: Moderna, 2018.

BIERWAGEN, Gláucia Silva. Uma proposta de uso do Blog como ferramenta de auxílio ao ensino de ciências nas séries finais do ensino fundamental. 190 p. (Tese de Doutorado) Universidade de São Paulo, São Paulo, 2011.

BISSOLOTTI, Katielen; GONÇALVES, Berenice; PEREIRA, Alice Theresinha Cybis. Design centrado na criança: estudo de recomendações para uma boa experiência. Revista Eletrônica Blucher Design Proceedings, v. 2, n. 1, jun. 2015, p. 1045-1055.

BOEIRA, Adriana Ferreira. Blogs na educação: blogando algumas possibilidades pedagógicas. Revista Tecnologias na Educação, n. 1, 2008, p. 1-11.

CGI. Comitê gestor da internet no Brasil. 2018. Disponível em: <https://cgi.br>. Acesso em: 10 jan. 2020. 
CUNHA, Nathália Saatman Matos da. Vamos fazer um Blog na escola? O Blog como mediador de aprendizagens no ensino fundamental. 73p. (Trabalho de Conclusão de Curso de Graduação) - Universidade Federal do Rio Grande do Norte, Natal, 2015.

CZERWINSKI, Gabriela Petró Valli; COGO, Ana Luisa Petersen. Webquest e Blog como estratégias educativas em saúde escolar. Revista Gaúcha de Enfermagem, v. 39, fev./ set. 2018. p 1-6.

PRIBERAM. Dicionário da língua portuguesa. Disponível em: <http://www.priberam.pt/>. Acesso em: 28 mar. 2020.

ESCOBAR, Juliana L. Blogs jornalísticos: propondo parâmetros para uma definição mínima. In: ENCONTRO DA ASSOCIAÇÃO BRASILEIRA DE PESQUISADORES EM JORNALISMO SBPJor, 5, 2007, Aracaju. Proceedings of the 5th Encontro da Associação Brasileira de Pesquisadores em Jornalismo-SBPJor, p. 1-13.

FREIRE, Karine Xavier; RODRIGUES JUNIOR, José Florêncio. Webquest: uma pesquisa ação de seu emprego no ensino Fundamental. In: CONGRESSO NACIONAL DE EDUCAÇÃO PUCPR, 9, 2010, Curitiba. Anais do IX Congresso Nacional de Educação PUC-PR. p. 6309 - 6319.

LAIS, Cláudia. O uso dos gêneros digitais na sala de aula. Educação e Comunicação, Cadernos de Graduação, v. 3, n. 2, 2016, p 175-188.

MORAES, R.; GALIAZZI, M. do C. Análise textual discursiva. ljuí: Ed. Unijuí, 2016.

MORAIS, Daiane Aparecida Miliossi. Uma aplicação de Vlogs nas aulas de estatística na educação básica. 77 p. (Dissertação de Mestrado) - Universidade Tecnológica Federal do Paraná, Londrina, 2017.

OLIVEIRA, Janaína Fátima Sousa. Estratégias de trabalho com Blogs no ensino de geometria em turmas de $5^{\circ}$ ano do ensino fundamental. 151 p. (Dissertação de Mestrado) - Universidade Federal de Uberlândia, Uberlândia, 2016.

ONO, Keiko. Uso das mídias como ferramenta para trabalhar dificuldades de aprendizagem na alfabetização de alunos do ensino fundamental. 51 p. (Trabalho de Conclusão de Curso) - Universidade Federal do Rio Grande do Sul, Porto Alegre, 2015.

SANTOS, Ademir José dos; GROSSI, Márcia Gorett Ribeiro; PARREIRAS, Maria de Lourdes. O Blog como recurso pedagógico no processo de ensino e aprendizagem. Revista Lugares de Educação, v. 4, n. 8, 2014, p. 92-109.

SENRA, Marilene Lanci Borges. Uso do Blog como ferramenta pedagógica nas aulas de língua portuguesa. Revista Diálogo e Interação, v. 5, 2011, p. 1-13.

SILVA, Adriana da. Blog educacional: o uso das novas tecnologias no ensino. Vertentes, n. 31, jan./jun 2008, p. 75-84. 
SILVA, Aléx Gomes da. Gitahy, Raquel Rosan Cristino. O uso do Blog no âmbito escolar: uma investigação no programa educacional de atenção ao jovem-PEAS Juventude. Revista Eletrônica Pedagogia em Foco, n. 8, 2013, p. 3-25.

SILVA, Nívea Rohling da. Práticas de leitura: a utilização do Blog em sala de aula. Revista Texto Digital, v. 2, n. 2, 2006, p. 1-19. Disponível em: < https://periodicos.ufsc.br/index.php/textodigital/article/view/1378/1077 > . Acesso em: 10 jan. 2020.

SOUZA, Albanyra dos Santos. Gêneros discursivos digitais na formação docente: o Blog em práticas de ensino. 123 p. (Dissertação de Mestrado) - Universidade Federal do Rio Grande do Norte, Natal, 2016.

VALENTE, José Armando. As tecnologias digitais e os diferentes letramentos. Revista Pátio, v. 11, n. 44, 2007, p. 12-15.

VALLI, Gabriela Petró. Blog escolar como estratégia de educação em saúde. 75 p. (Dissertação de Mestrado) - Universidade Federal do Rio Grande do Sul, Porto Alegre, 2015.

Recebido em: 03/07/2020

Parecer em: 09/07/2020

Aprovado em: 03/08/2020 